Article

\title{
Study of the Effect of Surface Treatment on the Chloride Ion Transport at the Cementitious Spacer-Concrete Interface
}

\author{
Yibo Yang ${ }^{1,2}, *$, Chen Huang ${ }^{3}$, Wenying Guo ${ }^{1}$, Hui Zhao ${ }^{1}$, Zhenjie $\mathrm{Li}^{4}$, Jiankuan $\mathrm{Li}^{1}$, \\ Jianyong Bao ${ }^{1}$ and Hengchang Wang ${ }^{1}$ \\ 1 School of Civil Engineering and Transportation, South China University of Technology, \\ Guangzhou 510640, China; wyguo@scut.edu.cn (W.G.); z.hui05@mail.scut.edu.cn (H.Z.); \\ li.jiankuan@mail.scut.edu.cn (J.L.); bao.jy@mail.scut.edu.cn (J.B.); cthcwang@scut.edu.cn (H.W.) \\ 2 State Key Laboratory of Subtropical Architecture Science, South China University of Technology, \\ Guangzhou 510640, China \\ 3 Department of Civil, Geomatic and Environmental Engineering, University College London, \\ London WC1E 6BT, UK; chen.huang.14@ucl.ac.uk \\ 4 Guangzhou Hanhua Architects + Engineers Co., Ltd., Guangzhou 510655, China; lizhenjie@gzhanhua.com \\ * Correspondence: yangyibo@scut.edu.cn; Tel.: +86-1371-091-4657
}

Received: 21 June 2020; Accepted: 23 July 2020; Published: 28 July 2020

check for updates

\begin{abstract}
Spacers are important components in reinforced concrete structures to provide cover between the steel reinforcement and the formwork. Cementitious spacers are of particular interest for coastal engineering structures, as they are compatible with cement-based chloride-resistant high-performance concrete compared to plastic and steel spacers. However, the cementitious spacer-concrete interface was found to be highly porous and microcracked. This study investigated the effect of surface treatment on the chloride ion transport at the cementitious spacer-concrete interface. A surface treatment technique for potential mass production was introduced and the state-of-practice tests of the hardened concrete were modified to evaluate the performance of the spacer-concrete composite specimens. The results showed that the surface treatment on a cementitious spacer improved the bonding between the spacer and concrete at the interface. The surface treatment of the spacer improved the compressive strength and the chloride resistance of the composite specimen locally compared to those without surface treatment. The advantage of surface treatment on the chloride resistance was partially represented in either the diffusion coefficient or the column electric flux. The maximum chloride ion penetration depth at the spacer-concrete interface was recommended as an additional proxy for the evaluation of the chloride resistance performance of composite specimens.
\end{abstract}

Keywords: surface treatment; cementitious spacer; chloride resistance; concrete

\section{Introduction}

Spacers are important components in reinforced concrete structures to provide adequate cover between the steel reinforcement and formwork or the nearest concrete face. Although the small spacers seem inconsequential compared to the overall reinforced concrete structure, they are indeed vital to ensure the correct placement of reinforcement to the design requirements and to produce durable reinforced concrete [1,2]. Spacers of various shapes and sizes are utilised in the construction industry and they can be generally classified into three categories based on the materials: cementitious spacer, plastic spacer, and steel chair. As the steel chair is welded to the reinforcement cages, it is recommended [1] that the steel chair should not be used off faces exposed to aggressive agents (e.g., chloride ion). The plastic spacers were found to be susceptible to degradation by ultra-violet 
radiation [1] and among the three types of spacers, to have the largest increase in the transport of aggressive agents when exposed to the marine environment [3]. The cementitious spacer, if not carefully designed (i.e., the mix design) or manufactured, could also result in early corrosion at the spacer location as observed in the field investigation [4,5]. Thus, for the construction of reinforced concrete structure subjected to extreme weathering and chemical corrosion in offshore areas, the cementitious spacers were widely used because of the desired engineering properties of cement, which can be designed to have comparable strength, durability, and porosity to the surrounding cement-based chloride-resistant high-performance concrete (HPC).

The engineering concern of permanently leaving considerable amounts of spacers along the reinforcement in a structure is that the presence of spacers potentially facilitates the ingress of aggressive agents $[2,6]$ through paths such as the spacer itself, or its interface with concrete, in addition to the concrete near the spacer, as illustrated in Figure 1. The quality (e.g., microstructure, porosity) of the spacer and the surrounding concrete (i.e., the possible penetration path 1 and 3 in Figure 1) can be improved by carefully calibrated variables, such as water-to-binder ratio (W/B), the type and amount of mineral admixtures as well as the maximum size of aggregates. Extensive researches [7-10] have been conducted in this regard and conclusions have been applied in the construction industry to build durable costal structure e.g., [11]. However, although the spacer-concrete interface has been well recognised as a weak link with regard to ingress in practice, only a few laboratory investigations $[2,12]$ are available to explain the phenomena and to improve the interface. Furthermore, limited guidance on the evaluation of the properties of the spacer and its collective performance with concrete, particularly at the spacer-concrete interface, is available for site engineers and contractors.

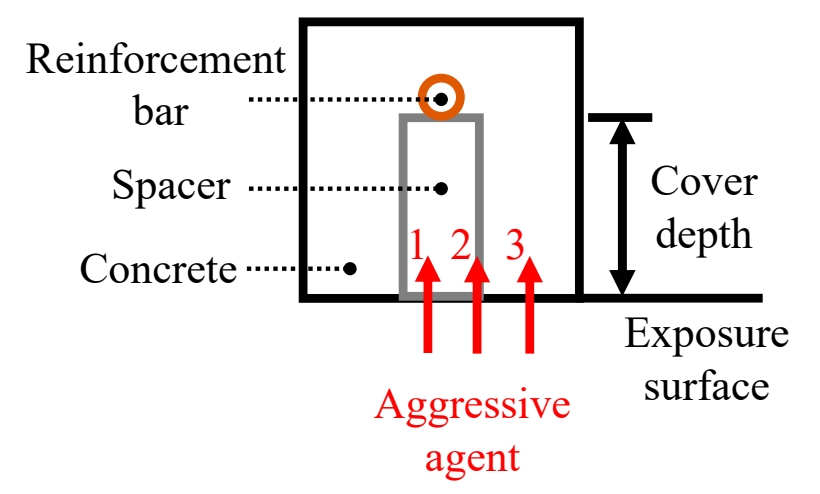

Figure 1. Schematic plot of the possible penetration paths of the aggressive agent through (1) the spacer, and (2) the interface between the spacer and concrete, and (3) the concrete.

The state-of-practice codes and standards [13-17] provide general specifications on the spacers and their placement. It is specified that the spacer should be durable and it should not lead to the corrosion of reinforcement or the spalling of concrete cover. Moreover, the spacer should be fixed to reinforcement bars at a spacing not exceeding 50 times the diameter of the rebar or $1000 \mathrm{~mm}$ and the layout of the spacer can be in staggered rows for parallel bars. However, the code-of-practice neither offers guidance on how to reduce the negative effects of spacers nor provides a recommendation on the performance testing of the spacer itself or the spacer-concrete specimen.

The recent laboratory findings have advanced the knowledge of the production and application of the spacers. The study conducted by Alzyoud et al. $[2,18]$ has systematically evaluated the effects of commercial spacers on the mass transport properties and the microstructure between the spacer and concrete. The results from a series of experiments on assorted spacers have shown that spacers increase the mass transport, which is due to a porous spacer-concrete interface that spans the cover where preferential transport occurs. By investigating the reinforced concrete columns exposed in the tidal zone for more than 30 years, the study of Strømme [19] also observed that the presence of plastic spacer increased the chloride penetration along with the spacer-concrete interface. Therefore, it is of 
great engineering importance to improve the interface between the spacer and concrete so that the overall structure reaches the expected design performance, particularly the durability and mechanical properties. The quality of the spacer-concrete interface could be influenced by its rough surface texture. Muslim et al. [12] have introduced a range of surface textures to semi-circular cementitious spacers that were later cast into the concrete to form the cylindrical specimens. Their tests on composite specimens have shown that spacer surface texture positively contributes to its interlocking with concrete, leading to a significant improvement in the bond strength of the spacer-concrete interface. However, the effect of surface textures on mass transport properties has remained unclear.

These codes of practice and research conclusions have significant implications on the construction practice, such as the surface treatment of spacers on construction sites and the spacer-concrete performance testing during the construction processes. Following the current spacer specifications and suggestions, the spacer should be compatible with the surrounding concrete in terms of mechanical property and durability. Moreover, the spacer should be manufactured in a factory or prepared on the construction site in such a way that it has an adequately rough surface to increase the bonding with concrete at the spacer-concrete interface. Furthermore, the state-of-practice testing of the hardened concrete (i.e., taking a sample of the fresh concrete on site and testing the corresponding hardened concrete for compressive strength and other engineering properties) can be adapted to evaluate the performance of a spacer-concrete composite specimen (i.e., composed of the fresh concrete and the spacer that is used on site) through compressive strength testing as well as other durability tests. By testing the quality of the spacer and the spacer-concrete composite specimen during the construction process, the structural design can be conducted properly (e.g., with sufficient cover and the correct position of reinforcement bar). Moreover, it also provides a long-term estimation of construction performance, particularly at the spacer location, to avoid or mitigate the undesirable corrosion observed in the field investigation.

This study investigated the influence of surface treatment on the performance of a chloride-resistant spacer-concrete composite specimen. In the following section, the methodology utilised in this study is described. In particular, the preparation of the spacer-concrete composite specimen and the modified testing method for the resistance to the chloride ion of the composite specimen were introduced. The results of the compressive strength and the chloride-resistance properties of the composite specimen were discussed. Recommendations on the manufacturing of spacers with a rough surface in a factory and on the testing of the spacer-concrete composite specimen were provided based on the results of this study.

\section{Materials and Methods}

\subsection{Materials}

The following materials were used for the mix of the chloride-resistant spacer and HPC and the associated properties are as follows:

1. Portland cement CEM II $42.5 \mathrm{R}$ was used for all mixes. The density, the specific area, and the water requirement of standard consistency were $2.97 \mathrm{~g} / \mathrm{cm}^{3}, 380 \mathrm{~m}^{2} / \mathrm{kg}$, and $25.2 \%$, respectively. The soundness conformed to British standard BS EN 197-1:2011 [20]. The initial and final setting times were $183 \mathrm{~min}$ and $275 \mathrm{~min}$, respectively. The 3 day and 28 day flexural strengths were 6.3 MPa and 9.0 MPa, respectively. The 3 day and 28 day compressive strengths were $29.7 \mathrm{MPa}$ and $58.4 \mathrm{MPa}$, respectively.

2. Fly ash was produced from the burning of anthracite or bituminous coal with a density of $2.19 \mathrm{~g} / \mathrm{cm}^{3}$. The fineness was $23.6 \%$, classified as category $\mathrm{N}$, and the loss on ignition was $4.84 \%$, classified as category A, conforming to British standard BS EN 450-1:2012 [21]. The water requirement was $98 \%$. 
3. Ground-granulated blast slag (GGBS) was used. The density and the specific area were $2.82 \mathrm{~g} / \mathrm{cm}^{3}$ and $440 \mathrm{~m}^{2} / \mathrm{kg}$, respectively. The 7 day and 28 day activity indexes were $87 \%$ and $102 \%$, respectively, conforming to British standard BS EN 15167-1:2006 [22].

4. Sand with a maximum particle size of $5 \mathrm{~mm}$ was used as the fine aggregate. The fineness modulus of sand was 2.3, complying with British standard BS EN 12620:2002+A1:2008 [23] medium grading. The pre-dried particle density was $2754 \mathrm{~kg} / \mathrm{m}^{3}$. The loose bulk density and the percentage of voids were $1448 \mathrm{~kg} / \mathrm{m}^{3}$ and $47.4 \%$, respectively.

5. Two types of gravel (of 5-10 $\mathrm{mm}$ particle size and of 10-20 mm particle size) were used as the coarse aggregate (denoted as G5-10 and G10-20, respectively). The pre-dried particle density, the loose bulk density, and the percentage of G5-10 were $2685 \mathrm{~kg} / \mathrm{m}^{3}, 1278 \mathrm{~kg} / \mathrm{m}^{3}$, and $52.4 \%$, respectively. The pre-dried particle density, the loose bulk density, and the percentage of G10-20 were $2738 \mathrm{~kg} / \mathrm{m}^{3}, 1451 \mathrm{~kg} / \mathrm{m}^{3}$, and $47.0 \%$, respectively. G5-10 and G10-20 were mixed by a 2:3 ratio by mass to comply with the British standard BS EN 12620:2002+A1:2008 [23] overall grading (denoted as G5-20).

6. Polycarboxylate superplasticiser produced by Guangdong Jiangmen Qiangli Building Material Technology Co., Ltd., was used. The solid content was $20 \%$.

7. A retarder was used as the surface treating agent. The retarder was mainly made of the sodium gluconate retarder for concrete, which had a notable retardation effect. The solid content was $20 \%$ and the usage of the retarder for the surface treatment of the spacer was about $0.2 \sim 0.3 \mathrm{~kg} / \mathrm{m}^{2}$.

8. Tap water was used as the batch water.

\subsection{Mix Design of Concrete and Spacers}

The mix proportions of the chloride-resistant HPC, chloride-resistant small-size coarse aggregate concrete spacer and chloride-resistant mortar spacer (hereafter denoted as C, SS, and MS, respectively) are presented in Table 1. Tang and Utgenannt [5] have suggested that the corrosion at the spacer locations may be due to the highly porous structure within the spacer itself. The supplementary cementitious materials (e.g., GGBS and fly ash) and polycarboxylate-based admixture were considered in the mix of concrete and spacer to improve their microstructures, as several studies [24] showed that these materials had a positive influence on the chloride resistance of concrete.

Table 1. Mix proportions of concrete and spacers.

\begin{tabular}{ccccccc}
\hline Mix ID & W/B & $\begin{array}{c}\text { Total Binder } \\
\left(\mathbf{k g} / \mathbf{m}^{\mathbf{3}}\right)\end{array}$ & $\begin{array}{c}\text { GGBS } \\
\text { Dosage (\%) }\end{array}$ & $\begin{array}{c}\text { Fly Ash } \\
\text { Dosage } \mathbf{( \% )}\end{array}$ & $\begin{array}{c}\text { Superplasticiser } \\
\mathbf{( \% )}\end{array}$ & $\begin{array}{c}\text { Sand Ratio } \\
\mathbf{( \% )}\end{array}$ \\
\hline $\mathrm{C}^{*}$ & 0.35 & 430 & 50 & 15 & 1.5 & 40 \\
$\mathrm{SS}+$ & 0.36 & 500 & 33 & 27 & 1.2 & 50 \\
MS & 0.36 & 625 & 33 & 27 & 1.2 & 100 \\
\hline
\end{tabular}

* G5-20 aggregate was used for the chloride-resistant HPC(C). + G5-10 coarse aggregate was used for the small-size coarse aggregate concrete spacer (SS).

\subsection{Preparation of Spacers}

The spacers used in this study were prepared in a manner that could be easily integrated with the current manufacturing process in a spacer factory. Through a field investigation of the spacer manufacturers and construction sites in Guangzhou, China, it was observed that commercial cementitious spacers are produced in a relatively short time (i.e., the average time for the mixing and curing of a spacer among the investigated factories was 5 days) compared with the time needed for the preparation of the standard concrete specimen (i.e., 28 days). This is because the economic cost of manufacturing spacers (e.g., materials, equipment, labour) would increase as the manufacturing time increases, leading to decreased benefits. Moreover, it has been noted that the water curing method is adopted at the early stage of the cement-hardening process in most manufacturing processes, which is expected to improve the hydration of the cement and ensure the strength development and 
low-porosity of the inner structure of the spacer. Additionally, after water curing for a certain amount of time, the cementitious spacers were usually exposed to the air to complete the drying process, which reduces the curing cost and also prepares the spacers in a convenient state for trade and transport. Taking the aforementioned manufacturing process into account, the spacers in the present study are prepared through the following steps:

1. The mixed materials of the chloride-resistant small-size coarse aggregate concrete spacers (SS) and chloride-resistant mortar spacers (MS) were cast into a $40 \mathrm{~mm} \times 40 \mathrm{~mm} \times 160 \mathrm{~mm}$ rectangular steel mould and were unmoulded after $24 \mathrm{~h}$;

2. The spacers were first cured in water at $20{ }^{\circ} \mathrm{C}$ for 3 days and then were exposed to the air at room temperature for 1 day;

3. The spacers were cut to the size of $40 \mathrm{~mm} \times 40 \mathrm{~mm} \times 80 \mathrm{~mm}$ for the subsequent experiments.

It is worth pointing out that the considered curing scheme for spacers is plausible and efficient for mass production in a factory and the optimal curing scheme is currently under investigation by the authors of this study. Other factors (e.g., dehydration due to the time lag between the manufacturing and application of spacers) that may affect the quality of the spacers were beyond the scope of this study.

\subsection{Surface Treatment of Spacers}

The surface treatment of spacers aimed to roughen the surface of the spacers to improve the adhesion and bonding between the spacer and the concrete at the interface. Alzyoud et al. [2] utilised sandpaper or scored the notches on plastic spacers to improve the quality of the spacer-concrete interface. However, these approaches may not be cost-effective for mass production in a factory, as it would require intensive labour and additional specialised apparatus. Muslim et al. [12] introduced surface textures to improve the spacer-concrete interface. Although this approach is promising, it is currently not practical for in-factory manufacturing, as it requires a set of new moulds with various surface textures that is not readily available.

In light of these surface-treatment approaches and the state-of-practice concrete production, the research presented in this paper has introduced a different surface treatment approach using a hardening retarder. The retarder is widely used in massive concrete construction (e.g., dam and deep beam) to slow the hardening of concrete and to release the heat of hydration over time. Using retarder on the surface of the spacers allows the cement on the surface to remain unset while the inner portion of each spacer reaches its initial setting time. After removing the surface laitance, the aggregate of the spacers would be partially exposed, forming a "natural" rough surface.

The proposed approach can be easily implemented within the current spacer manufacturing process. Specifically, before filling the spacer mould, the inner surface of the mould was covered with a thin film of retarder material to slow down the hardening of the cementitious material on the inner surfaces (i.e., the surfaces in contact with the mould). After filling the mould, the as-cast surface (i.e., the upper edge of the mould) was carefully levelled, on which a thin film retarder material was sprayed evenly. A spacer can only be unmoulded when its inner part reaches the initial setting time. The surface laitance was removed under running water before entering the water curing stage. Examples of spacer surface with and without this surface treatment are presented in Figure 2. Since the spacer was tiny in size and its surface area was small in quantity, the amount of retarder used per spacer was minimal compared to that usually used in the concrete design. The cost of the surface treatment agent per spacer in this study was negligible (around one cent U.S. dollar), which made it economically feasible for the mass production of spacers with surface treatment. 


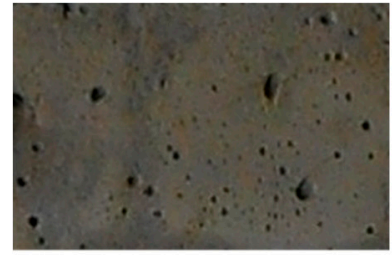

(a)

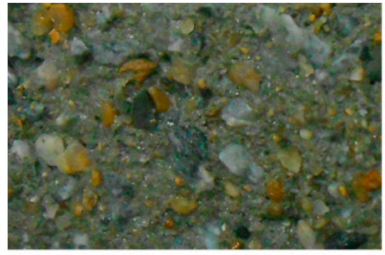

(b)

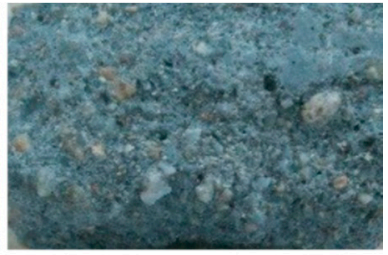

(c)

Figure 2. Examples of spacer surface with and without surface treatment: (a) the spacer without surface treatment; (b) the chloride-resistance small-size coarse aggregate concrete spacer (SS) with surface treatment; and (c) the chloride-resistant mortar spacer (MS) with surface treatment.

\subsection{Preparation of Spacers and Concrete Composite Specimen}

The composite specimen containing the spacer and concrete was designed to test the collective performance of the two components. Alzyoud et al. [2] have designed a cylindrical composite specimen of $100 \mathrm{~mm}$ in diameter and 25 or $50 \mathrm{~mm}$ in height, having the spacer in the middle of the bottom surface of the specimen (i.e., the lower edge of the mould). This type of composite specimen has been tested for the mass transport properties and to evaluate the microstructure of the spacer-concrete interface. Strømme [19] drilled cores of $100 \mathrm{~mm}$ in diameter containing spacer from the column of $1.2 \mathrm{~m}$ in length and $0.6 \mathrm{~m}$ in diameter, which were exposed to the marine environment. These samples were used to evaluate the influence of spacer on chloride diffusion and reinforcement corrosion in concrete. Muslim et al. [12] considered a cylindrical sample $100 \mathrm{~mm}$ in diameter and $50 \mathrm{~mm}$ in height that contained half-spacer and half-concrete for bond strength and mass transport testing. These types of cylindrical composite specimens have a similar diameter to the cylinder specimen used for the testing of hardened concrete in British standard BS EN 12390-1:2012 [25] (i.e., $d$ mm diameters and $2 d$ height, where $d$ could be $100 \mathrm{~mm}$ ), although the height of the composite specimen is considerably different from that of the concrete specimen.

It would be convenient for both the manufacturers and contractors if the spacer-concrete composite specimen conforms to a standardised shape and dimension as those specified for the hardened concrete testing. First, it will facilitate the quality control process, as the performance of a composite specimen with a spacer (i.e., compression strength and chloride resistance) can be directly compared with the control concrete specimen without a spacer, which helps examine whether the spacer and concrete as a whole meet the requirements of the structural designers and clients. Moreover, it takes advantage of the existing standards and apparatus for the testing of hardened concrete, although certain adaptations to the current practice and training for technicians and workers are needed.

This study proposes a spacer-concrete composite specimen based on the conventional cubic concrete specimen, as illustrated in Figure 3 . The $40 \mathrm{~mm} \times 40 \mathrm{~mm} \times 80 \mathrm{~mm}$ spacers with and without surface treatment were placed in the middle of the bottom surface of the $100 \mathrm{~mm}^{3}$ cubic steel mould and the chloride-resistant HPC Mix C was cast around the spacer. The spacer-concrete composite specimen was compacted in two layers and each layer was vibrated by a vibrating table until no significant release of air bubbles was observed. The spacers were manually held in place during the vibration process and the check showed little relative movement between the spacer and mould. It is worth noting that the vibrating table may not be available on the construction site for the preparation of composite specimens. Alternatively, compacting by hand with a compacting rob or bar is recommended and great care is needed to ensure that the spacer is in place. The composite specimen was cured in a fog room at a temperature of $20^{\circ} \mathrm{C} \pm 2{ }^{\circ} \mathrm{C}$ and a relative humidity of $\geq 95 \%$ for 28 days.

The composite specimens are labelled in the following order: spacer type-surface-treatmentconcrete. For example, the composite specimen comprising a small-size coarse aggregate concrete spacer (SS) with surface treatment (T) and chloride-resistant HPC (C) is referred to as the SS-T-C sample. 

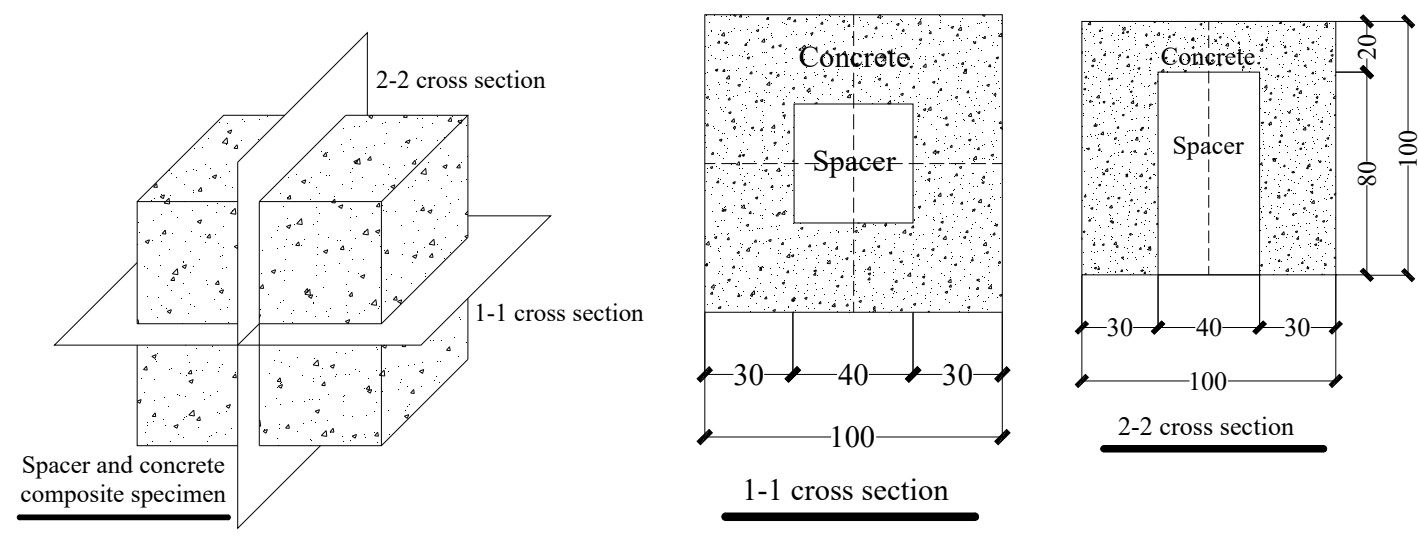

Figure 3. Spacer and concrete composite cross-sections (Unit: $\mathrm{mm}$ ).

\subsection{Test Methods}

In comparison with the testing of hardened concrete, Muslim et al. [12] applied the splitting tensile testing, conforming to British standard BS EN 12390-6:2009 [26], to the half-spacer and half-concrete composite specimen to estimate the interface bond strength between the spacer and the concrete. The same rationale can be extended to other existing test methods for hardened concrete.

The present study has applied the compressive strength testing, conforming to the China code GB/T 50081-2019 [27], to the 28 day and 56 day cubic composite specimens to determine the compressive strength, particularly at the spacer location. In GB/T 50081-2019 [27], the cubic specimen of $150 \mathrm{~mm}$ $\times 150 \mathrm{~mm} \times 150 \mathrm{~mm}$ was considered as the standard specimen and the compressive strength of the non-standard specimen should consider the size effect. In this study, the non-standard cubic specimen of $100 \mathrm{~mm} \times 100 \mathrm{~mm} \times 100 \mathrm{~mm}$ was utilised and a size-effect factor of 0.95 was applied according to the code. As the spacer locations in a real construction project are not specified by the structural designers, it is important to ensure that any spacer that replaces a portion of the concrete does not significantly impair the overall compressive strength.

This study evaluated the resistance of the composite specimen to chloride ion penetration by examining the diffusion coefficients and the coulomb electric flux from non-steady-state migration experiments conforming to the China code GB/T 50082-2009 [28]. The test methods in the China code for the evaluation of the rapid chloride migration coefficient $D_{R C M}$ and the coulomb electric flux follow the same principles as the European standard NT BUILD 492 [29] and the American standard ASTM C1202 [30], respectively. However, to identify the effect of spacers on the chloride resistance of the composite specimen, some modifications were made to the test methods. First, a slice $50 \pm 1 \mathrm{~mm}$ thick and $100 \mathrm{~mm}$ in diameter was cut from the bottom portion of the composite specimen and the surface that was nearer to the bottom surface (i.e., the opposite surface to the as-cast surface) is the surface exposed to the chloride solution. This modification on the preparation of the test specimen is intended to reproduce the actual chloride ion erosion process that begins from the exposed surface where the spacers are placed. Moreover, to estimate the long-term collective durability of the spacer and the concrete, the chloride ion diffusion testing was also performed on the 56 day composite specimen. The modified testing on the chloride resistance of the composite specimen may provide a straightforward evaluation of the composite specimen performance, particularly at the spacer-concrete interface.

\section{Results and Discussion}

\subsection{Compressive Strength}

The compressive strength results are presented in Figure 4. As shown, the compressive strengths of composite specimens were generally lower than that of the control chloride-resistant HPC (C), 
suggesting that a partial replacement of the concrete by the spacer would reduce the compressive strength of the specimen. Moreover, the compressive strength of the composite specimen with surface treatment (T) was approximately $5 \%$ higher than those without surface treatment $(\mathrm{N})$. This is expected as the surface treatment is intended to improve the bonding between the spacer and the concrete. Additionally, the compressive strength of the composite specimen containing the chloride-resistant mortar spacers (MS) was generally higher than those containing the small-size coarse aggregate concrete spacers (SS).

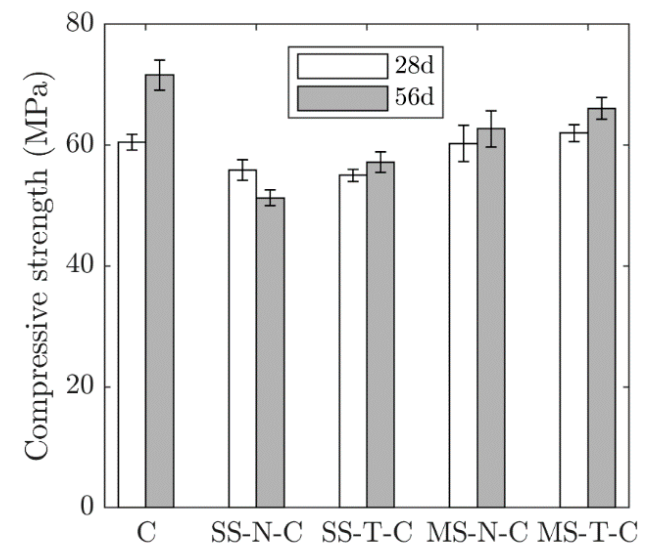

Figure 4. Compressive strengths of the specimens. The control chloride-resistant high-performance concrete was denoted by $\mathrm{C}$. The chloride-resistant small-size coarse aggregate concrete spacers and the chloride-resistant mortar spacers were denoted by SS and MS, respectively. The composite specimen with and without surface treatment were denoted by $\mathrm{T}$ and $\mathrm{N}$, respectively.

The theoretical and experimental failure modes of the spacer-concrete composite specimens under the compressive load are illustrated in Figure 5.

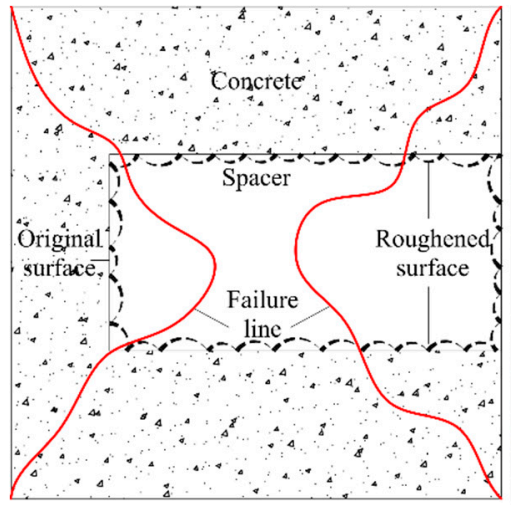

(a)

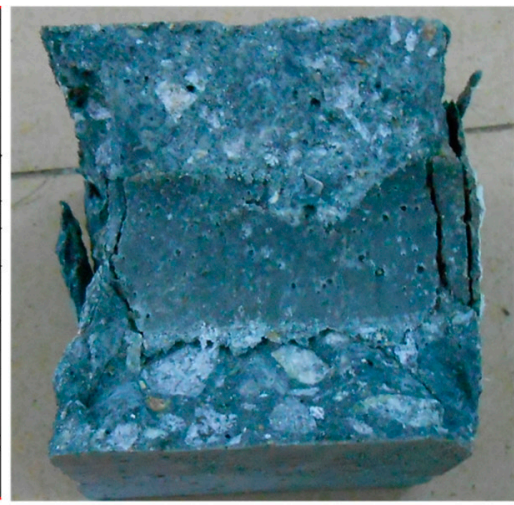

(b)

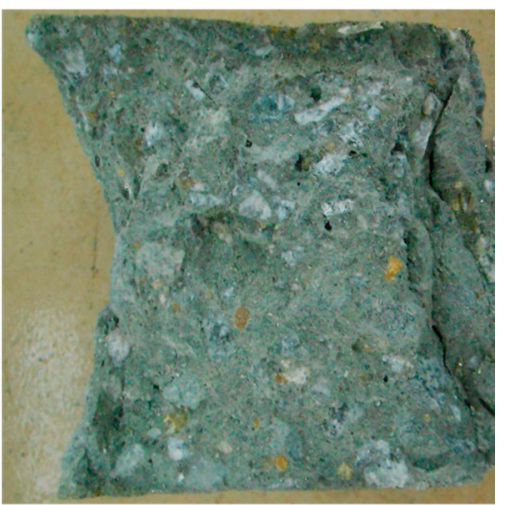

(c)

Figure 5. Failure modes of the spacer and concrete composite specimens after the compressive strength testing: (a) the theoretical failure mode of the spacer and concrete composite specimen, where the red line indicates the expected cracking pattern; (b) the composite specimen without surface treatment $(\mathrm{N})$; and (c) the composite specimen with surface treatment $(\mathrm{T})$.

As shown in Figure 5a, the spacer and concrete composite specimen (with a spacer $80 \mathrm{~mm}$ in height) was expected to fail along the red line due to the hoop effect, as an analogy to the concrete specimen. However, the composite specimen without the surface treatment of the spacer had an unsatisfactory failure mode as shown in Figure 5b. The applied compressive load crushed the specimen along the smooth spacer-concrete interface, suggesting that the bond between the spacer without surface treatment and concrete was weak. On the contrary, the composite specimen with surface 
treatment of the spacer presented a failure mode that was consistent with the theoretical failure mode (Figure 5c), suggesting that the bond between the spacer and concrete was sufficient. These results indicate that the surface treatment that allows the aggregate to be partially exposed can form a sufficient bond at the spacer-concrete interface, which locally improves the mechanical property of the composite specimen.

These results have important engineering implications in terms of the strength of the concrete structure. The overall resistance strength of the structure at the spacer location may be compromised due to the existence of the spacer. Moreover, when the critical load is applied at the spacer location, the concrete may crack along the smooth spacer-concrete interface, which can be avoided or mitigated by introducing the surface treatment of the spacer.

\subsection{Resistance to Chloride Penetration}

The chloride ion diffusion coefficients are presented in Figure 6. As shown, the 28 day $D_{R C M}$ values of composite specimens, except for the MS-T-C specimen, were generally higher than that of the control concrete specimen. The 56 day $D_{R C M}$ values of the composite specimens were slightly smaller than the control specimen except for the SS-T-C specimen. The 28 day $D_{R C M}$ values of the composite specimen with the surface treatment of the spacer were systematically smaller than those without surface treatment. Similar observations hold for the 56 day $D_{R C M}$ values for the composite specimens with mortar spacer. The composite specimens with mortar spacer (with or without surface treatment) had generally lower $D_{R C M}$ values than those with the small-size aggregate spacer.

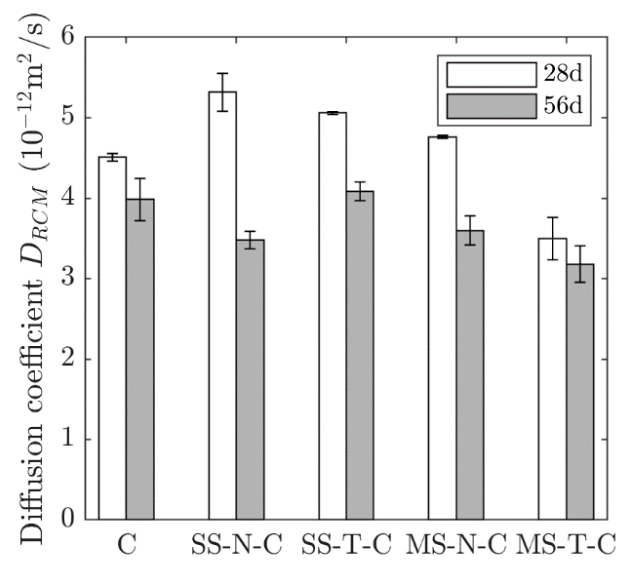

Figure 6. Chloride ion diffusion coefficient $D_{R C M}$.

These results suggest that the composite specimens with a spacer had a similar capacity to resist the chloride ion as the control concrete specimens over time. The lower 56 day $\mathrm{D}_{\mathrm{RCM}}$ values for the composite specimens compared to the control concrete may be because the cementitious spacer was prepared in advance and the total curing time of the spacer (i.e., the curing of the spacer and the curing of the composite specimen) was slightly longer, which will be further investigated in a future study. Moreover, the surface treatment could improve the resistance to chloride penetration at the spacer location.

It is worth noting that the calculation of the diffusion coefficient, $D_{R C M}$, was based on the average value of the penetration depth of the chloride ion at the split surface. To visualise the penetration depth, the $0.1 \mathrm{~mol} / \mathrm{L}$ silver nitrate solution was sprayed on to the freshly split section. It was observed that a higher-than-average penetration depth occurred at the spacer-concrete interface for the composite specimen without surface treatment, as presented in Figure 7a, which was considered to be a significant defect in the specimen and was ignored in the calculation of the diffusion coefficient. As presented in Figure $7 \mathrm{a}, \mathrm{c}$, regarding the composite specimen without the surface treatment of the spacer, the white silver chloride precipitation on the split surface presented a peak along the spacer-concrete interface, although the penetration depth in the spacer area was similar to that in the concrete area. In terms of 
the composite specimen with the surface treatment of the spacer (Figure $7 \mathrm{~b}, \mathrm{~d}$ ), the penetration front was nearly horizontal and no peculiar peak occurred at the spacer-concrete interface. These results suggest that surface treatment improves the quality of the spacer-concrete interface by forming a sufficient interlink with the concrete. Further analysis (e.g., microstructural analysis, scanning electron microscopy (SEM) or micro X-ray fluorescence ( $\mu$-XRF) elemental mappings) will be taken in the future study to visualise the chloride ingress.

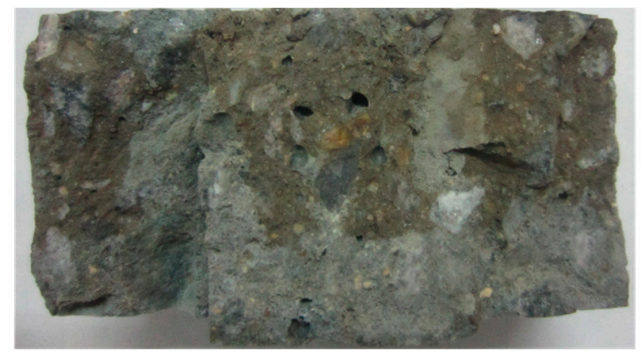

(a)

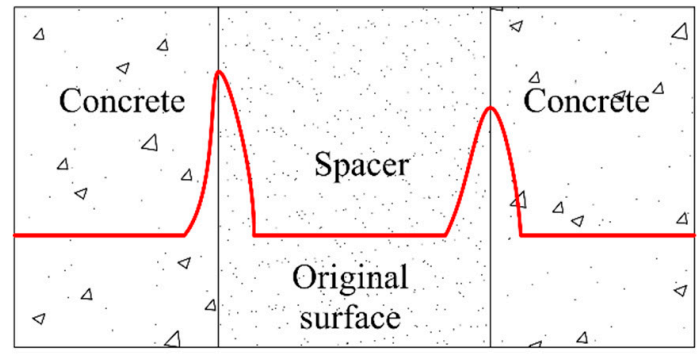

(c)

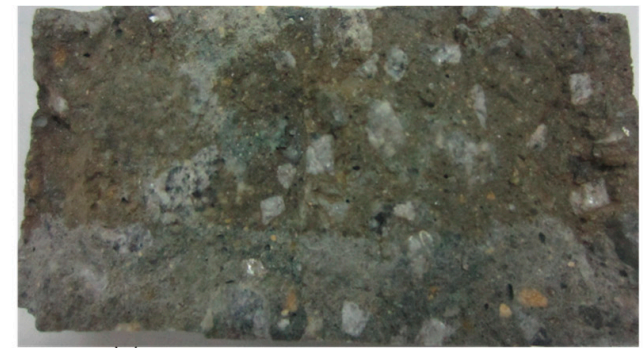

(b)

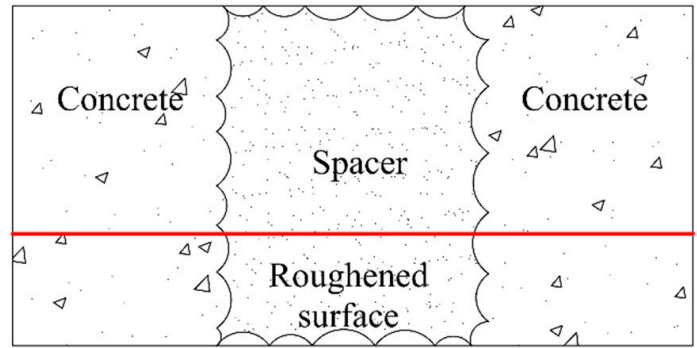

(d)

Figure 7. Chloride ion penetration depths of SS: (a) a picture of the split surface of the specimen without surface treatment where a significant defect at the spacer-concrete interface occurs; (b) a picture of the split surface of the specimen with surface treatment; (c) a schematic plot of the split surface of the specimen without surface treatment where a significant defect at the spacer-concrete interface occurs; and (d) a schematic plot of the split surface of the specimen with surface treatment.

The $6 \mathrm{~h}$ coulomb electric flux is presented in Figure 8. The 28 day coulomb electric flux of the composite specimen was lower than that of the control concrete, and the 56 day coulomb electric flux was similar between the composite specimen and the control concrete. The surface treatment of the spacer contributed positively to the resistance to chloride ion of the composite specimen with a mortar spacer while it negatively contributed to that with the small-size aggregate spacer. These results suggest that the benefit of surface treatment of the spacer is unclear.

It is worth noting that the aforementioned issue of the spacer-concrete interface (Figure 7) of the composite specimen without the surface treatment of the spacer also affected the testing of the coulomb electric flux. Since the chloride ion could deeply penetrate the composite specimen at the spacer-concrete interface, it also results in an excessively large electric flux which is considered as an outlier sample.

Several engineering implications can be drawn from these results. First, the surface treatment improved the quality of the spacer-concrete interface, judging from the penetration depth on the split surface of the composite specimen. Moreover, the effect of the surface treatment of the spacer to the chloride resistance capacity was partially observed in either the diffusion coefficient $D_{R C M}$ or the column electric flux, as the poor quality at the interface would result in the outlier data that were excluded in the data process. Additionally, for the evaluation of chloride resistance of the composite specimen in engineering practice, this study recommends to note and report the maximum chloride ion penetration depth at the spacer-concrete interface as an additional indicator to the diffusion coefficient 
$D_{R C M}$. If the maximum penetration depth at the interface is higher than the average penetration depth for a certain critical percentage, the spacer-concrete interface can be identified as a potential penetration path of an aggressive agent and the spacer would require surface treatment to improve the quality of the spacer-concrete interface and ultimately, the durability of the overall structure. Among the international standards of the testing of the resistance of concrete to chloride ion, the precision of testing and the identification of outliers vary. The Chinese standard GB/T 50082-2009 [28] has specified that the individual test determination that is more than $\pm 15 \%$ of the median diffusion coefficients or coulomb electric flux is an outlier. As per NT BUILD 492 [29] and ASTM C1202 [30], the coefficient of variation of the corresponding chloride resistance testing varies from approximately $10 \%$ to $30 \%$. As a rule of thumb, the critical percentage was recommended as 30\% (twice as the $15 \%$ tolerance per China code) taking into account the precision and practicality of this testing method.

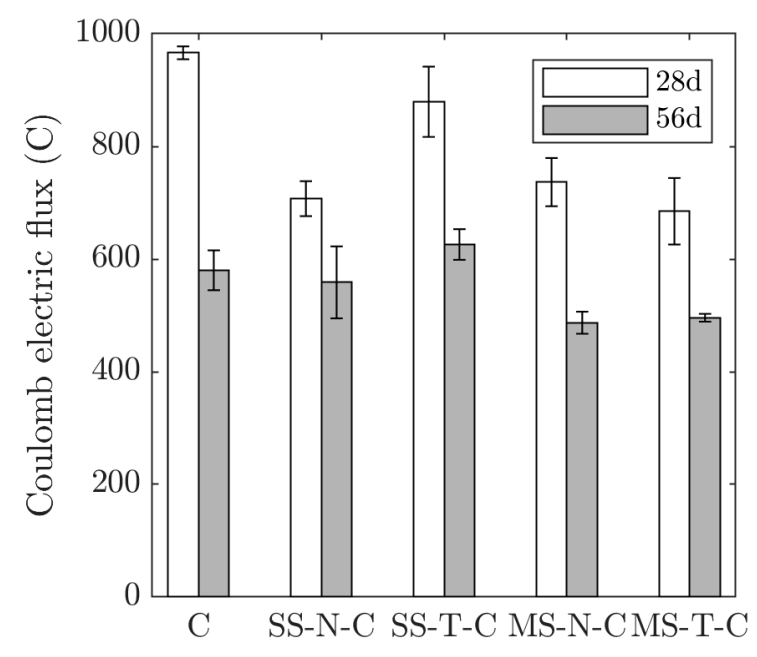

Figure 8. Six hour coulomb electric flux.

\section{Conclusions}

This study evaluated the influence of spacer surface treatment on the performance of chloride-resistant spacer and concrete composite specimens via the modified non-steady-state migration experiments, as well as the compressive strength. The surface treatment method proposed in this study can be adapted by spacer manufacturers for mass production. A spacer (both with and without surface treatment) $40 \mathrm{~mm} \times 40 \mathrm{~mm} \times 80 \mathrm{~mm}$ in size was placed in the middle of the bottom surface of a $100 \mathrm{~mm}^{3}$ cubic mould and formed a composite specimen with concrete. The composite specimen and testing method utilised in this study can be easily integrated with the state-of-practice testing of hardened concrete. The main conclusions are as follows:

- The surface treatment of the spacer had a positive effect on improving the bonding between the spacer and concrete at the interface. The surface treatment technique using retarder to roughen the surface of the spacer can be easily integrated within the current manufacturing process.

- The state-of-practice tests on the hardened concrete can be modified to evaluate the performance of the spacer-concrete composite specimens and provide an estimation of the long-term mechanical and durability properties of the structure at the spacer locations.

- The spacer-concrete composite specimen had a lower compressive strength and a similar resistance to the chloride ion than the control concrete.

- The surface treatment on the spacer improved the compressive strength of the spacer-concrete composite specimen locally, compared to those without surface treatment. The surface-treated spacer exposed a partial aggregate, thereby forming a sufficiently strong interlink at the concrete interface. The failure mode of the composite specimen with surface treatment of the spacer was 
similar to that of the concrete. However, the composite specimen without the surface treatment of the spacer experienced debonding at the interface when a critical load was applied.

- The surface treatment of the spacer improved the resistance to chloride ions of the composite specimen compared to those without surface treatment. The advantage of surface treatment was partially represented by either the diffusion coefficient $D_{R C M}$ or the column electric flux, as the poor quality at the interface would result in the outlier data that were excluded in the data process.

- The maximum chloride ion penetration depth at the spacer-concrete interface can be used as an additional proxy for the evaluation of the chloride resistance performance of composite specimens. If the maximum penetration depth at the interface is 1.3 times higher than the average penetration depth, the spacer-concrete interface can be identified to have a weak bond and the spacer would require surface treatment to improve the quality of the spacer-concrete interface.

Author Contributions: Conceptualization, Y.Y. and W.G.; supervision, Y.Y. and W.G.; project administration, C.H. and H.Z.; methodology, Y.Y., C.H., J.B.; investigation, C.H., H.Z., Z.L., J.L., J.B.; validation, C.H., H.Z., Z.L., J.L., J.B.; data curation, Z.L., J.L., J.B.; resources, H.W.; funding acquisition, Y.Y. and W.G.; visualisation, C.H.; writing-original draft, C.H.; writing-review and editing, Y.Y. and W.G. All authors have read and agreed to the published version of the manuscript.

Funding: This research was funded by the Water Resource Science and Technology Innovation Program of Guangdong Province, China (No. 2017-22).

Acknowledgments: The authors thank South China University of Technology for its technical support. The authors thank Wanli Fang for helping with the experiments. The authors thank two anonymous reviewers for the constructive comments and suggestions, which helped improve the quality of this paper.

Conflicts of Interest: The authors declare no conflict of interest.

\section{References}

1. Mackey, G.; Januszke, R. Influence of Bar Chairs, Spacers and Blocks on Concrete; Materials Technology Research and Development: Walkley Heights, Australia, 1995; pp. 1-49.

2. Alzyoud, S.; Wong, H.S.; Buenfeld, N.R. Influence of reinforcement spacers on mass transport properties and durability of concrete structures. Cem. Concr. Res. 2016, 87, 31-44. [CrossRef]

3. Danner, T.; Hornbostel, K.; Strømme, Ø.; Geiker, M.R. Self-Healing and Chloride Ingress in Cracked Cathodically Protected Concrete Exposed to Marine Environment for 33 Years; Norwegian University of Science and Technology: Trondheim, Norway, 2019; pp. 1-31.

4. Kenai, S.; Bahar, R. Evaluation and repair of Algiers new airport building. Cem. Concr. Compos. 2003, 25, 633-641. [CrossRef]

5. Tang, L.P.; Utgenannt, P. A field study of critical chloride content in reinforced concrete with blended binder. Mater. Corros. 2009, 60, 617-622. [CrossRef]

6. Angst, U.M.; Geiker, M.R.; Michel, A.; Gehlen, C.; Wong, H.; Isgor, O.B.; Elsener, B.; Hansson, C.M.; François, R.; Hornbostel, K.; et al. The steel-concrete interface. Mater. Struct. 2017, 50, 143. [CrossRef]

7. Song, H.W.; Lee, C.H.; Ann, K.Y. Factors influencing chloride transport in concrete structures exposed to marine environments. Cem. Concr. Compos. 2008, 30, 113-121. [CrossRef]

8. Amin, N.U.; Alam, S.; Gul, S. Effect of thermally activated clay on corrosion and chloride resistivity of cement mortar. J. Clean. Prod. 2016, 111, 155-160. [CrossRef]

9. He, X.; Shi, X. Chloride permeability and microstructure of Portland cement mortars incorporating nanomaterials. Transp. Res. Rec. J. Transp. Res. Board 2008, 2070, 13-21. [CrossRef]

10. Oh, B.H.; Cha, S.W.; Jang, B.S.; Jang, S.Y. Development of high-performance concrete having high resistance to chloride penetration. Nucl. Eng. Des. 2002, 212, 221-231. [CrossRef]

11. Cheewaket, T.; Jaturapitakkul, C.; Chalee, W. Concrete durability presented by acceptable chloride level and chloride diffusion coefficient in concrete: 10-year results in marine site. Mater. Struct. 2014, 47, 1501-1511. [CrossRef]

12. Muslim, F.; Wong, H.S.; Buenfeld, N.R. Improving the Spacer-Concrete Interface for Bond Strength and Durability. In Proceedings of the 6th International Conference on Durability of Concrete Structures (ICDCS 2018), Leeds, UK, 18-20 July 2018. 
13. American Concrete Institute. ACI 315-99: Details and Detailing of Concrete Reinforcement; American Concrete Institute: Farmington Hills, MI, USA, 1999.

14. American Concrete Institute. ACI SP-66: ACI Detailing Manual; American Concrete Institute: Farmington Hills, MI, USA, 2004.

15. British Standards Institution. BS 7973-1:2001: Spacers and Chairs for Steel Reinforcement and Their Specification-Part 1: Product Performance Requirements; British Standards Institution: London, UK, 2001.

16. British Standards Institution. BS 7973-2:2001: Spacers and Chairs for Steel Reinforcement and Their Specification-Part 2: Fixing and Application of Spacers and Chairs and Tying of Reinforcement; British Standards Institution: London, UK, 2001.

17. Subramanian, N.; Geetha, K. Concrete cover for durable RC structures. Indian Concr. J. 1997, 71, $197-201$.

18. Alzyoud, S. Effect of Reinforcement Spacers on Concrete Microstructure and Durability. Ph.D. Thesis, Imperial College London, London, UK, 2015.

19. Strømme, Ø. Influence of Cracks on Chloride Diffusion and Reinforcement Corrosion in Concrete. Master's Thesis, Norwegian University of Science and Technology, Trondheim, Norway, 2017.

20. British Standards Institution. BS EN 197-1:2011: Cement_Part 1: Composition, Specifications and Conformity Criteria for Common Cements; British Standards Institution: London, UK, 2011.

21. British Standards Institution. BS EN 450-1:2012: Fly Ash for Concrete-Part 1: Definition, Specifications and Conformity Criteria; British Standards Institution: London, UK, 2012.

22. British Standards Institution. BS EN 450-1:2006: Ground Granulated Blast Furnace Slag for Use in Concrete, Mortar and Grout-Part 1: Definitions, Specifications and Conformity Criteria; British Standards Institution: London, UK, 2006.

23. British Standards Institution. BS EN 12620:2002+A1:2008: Aggregates for Concrete; British Standards Institution: London, UK, 2002.

24. Lee, T.; Lee, J. Evaluation of Chloride Resistance of Early-Strength Concrete Using Blended Binder and Polycarboxylate-Based Chemical Admixture. Appl. Sci. 2020, 10, 2972. [CrossRef]

25. British Standards Institution. BS EN 12390-1:2012: Testing Hardened Concrete_Part 1: Shape, Dimensions and Other Requirements for Specimens and Moulds; British Standards Institution: London, UK, 2012.

26. British Standards Institution. BS EN 12390-6:2009: Testing Hardened Concrete-Part 6: Tensile Splitting Strength of Test Specimens; British Standards Institution: London, UK, 2009.

27. China Ministry of Housing and Urban-Rural Development. GB/T 50081-2019: Standard for Test Methods of Concrete Physical and Mechanical Properties; China Ministry of Housing and Urban-Rural Development: Beijing, China, 2019.

28. China Ministry of Housing and Urban-Rural Development. GB/T 50082-2009: Standard for Test Methods of Long-Term Performance and Durability of Ordinary Concrete; China Ministry of Housing and Urban-Rural Development: Beijing, China, 2009.

29. Nordtest. NT BUILD 492: Concrete, Mortar and Cement-Based Repair Materials: Chloride Migration Coefficient from Non-Steady-State Migration Experiments; Nordtest: Espoo, Finland, 1999.

30. American Society for Testing and Materials. ASTM C1202: Standard Test Method for Electrical Indication of Concrete's Ability to Resist Chloride Ion Penetration; American Society for Testing and Materials: West Conshohocken, PA, USA, 2019.

(C) 2020 by the authors. Licensee MDPI, Basel, Switzerland. This article is an open access article distributed under the terms and conditions of the Creative Commons Attribution (CC BY) license (http://creativecommons.org/licenses/by/4.0/). 